\title{
A case of renal allograft-related inflammation complicated by acute coronary syndromes
}

Rainer U. Pliquett ${ }^{1,2}$, Andrea Tannapfel ${ }^{3}$, Sait S. Daneschnejad ${ }^{4,5}$

'Dept. of Nephrology, Diabetology and Endocrinology, University of Leipzig, ${ }^{2}$ Dept. of Nephrology \& Diabetology, Carl-Thiem Hospital Cottbus, ${ }^{3}$ Institute of Pathology, Ruhr-University Bochum, ${ }^{4}$ Dept. of Cardiology, Helios Hospital Schkeuditz, ${ }^{5}$ Dept. of Cardiology, University of Leipzig, Germany

Running Title: Inflammation and acute coronary syndromes For consideration of publication in "Case Reports in Nephrology and Dialysis"

Words: Abstract: 167, Body: 1080

2 Figures

Correspondence to:

Rainer U. Pliquett, MD, PD

Carl-Thiem Hospital

Thiemstr. 111

D - 03048 Cottbus, Germany

Phone +4917670103873

Fax: +49355462240

Email: rpliquett@endothel.de 


\begin{abstract}
:
Background: Although persistent systemic inflammation is considered to be predictive for future cardiovascular events, it remains unclear whether or not Creactive protein $(\mathrm{CrP})$ plays an active role in coronary-plaque instability. Here, we report a case of a patient with failed and super-infected renal allograft as a source for systemic inflammation presenting with repeat acute coronary syndromes.
\end{abstract}

Case presentation: A 52-years-old male type-2 diabetic with a failed kidney transplant who was hospitalized for acute urinary-tract infection. In the presence of other, classic cardiovascular risk factors, peak values of $\mathrm{CrP}$ coincided with episodes of unstable angina treated by percutaneous coronary interventions. Besides pyelonephritis, the histological examination of the kidney transplant revealed signs of chronic rejection and the presence of a renal cell carcinoma in situ. Once the renal allograft has been removed, systemic inflammation was attenuated, the patient was not re-hospitalized for acute-coronary syndrome within the next 12 months.

Conclusion: In this case, systemic inflammation was paralleled by instability of coronary plaques as documented by repeat percutaneous coronary interventions.

Key Words: coronary artery disease, acute coronary syndrome, inflammation, case report 


\section{Background}

C-reactive protein ( $\mathrm{CrP})$, a surrogate of systemic inflammation, is considered to be a predictor for cardiovascular risk in the general population (1-3) as well as for the outcome in patients with acute myocardial infarction (4) or unstable angina (5). However, it remains unclear, whether or not CrP plays an active role in atherothrombosis or solely represents an epiphenomenon in acute coronary syndrom (6).

Here we report a patient with end-stage renal disease (ESRD) due to a failed, super-infected renal allograft hospitalized for repeat episodes of acute coronary syndrome. The role of systemic inflammation for coronary-artery disease outcomes is discussed. 


\section{Case presentation}

A 52-years-old, obese male patient with ESRD due to diabetic nephropathy was admitted to a nephrology department of a tertiary referral hospital because of haematuria, leukocyturia and oligo-anuria in the presence of a failed renal allograft. The patient received the renal allograft of a deceased donor 4 years earlier after 7 years of hemodialysis treatment. Hemodialysis treatment had to be resumed 6 months prior to hospitalization. Comorbidities include the full range of type-2-diabetes complications, rheumatic arthritis, secondary hyperparathyroidism, an epoetin-resistant anemia (haemoglobin at admission: $5.4 \mathrm{mmol} / \mathrm{l}$, ferritin: $1302 \mathrm{ng} / \mathrm{ml}$ ), and a history of multiple percutaneous coronary interventions for myocardial revascularization in the preceding six years. Leftventricular systolic function was preserved. The patient received an intensive insulin treatment in addition to standard cardiovascular medications including angiotensin converting enzyme inhibitor, statin, low-dose aspirin and betablocker agent and epoeitin alpha.

The eve prior to admission, the patient had chest pain. However, no action was taken. At admission, troponin $\mathrm{T}$ was slightly elevated $(0.15 \mu \mathrm{g} / \mathrm{L})$, creatinine kinase was normal. CrP $(155.1 \mathrm{mg} / \mathrm{L})$ and procalcitonin $(1.38 \mathrm{ng} / \mathrm{mL})$ were elevated. The ECG remained unchanged showing pre-existing T-wave inversions in I and aVL. Transthoracic echocardiography revealed a moderate leftventricular hypertrophy and a new inferoseptal and basoapical hypokinesia. Consecutively, a coronary angiography and bare-metal stent deployment into a right-coronary-artery stenosis were performed. Intravenous ciprofloxacin was administered for urinary-tract infection, CrP levelled off at $52 \mathrm{mg} / \mathrm{L}$. For persistent infection, an elective renal allograft-removal surgery was scheduled after discharge, once dual anti-platelet therapy for direct stenting was changed to monotherapy with low-dose aspirin. However, three weeks later, the patient was readmitted for acute coronary syndrome. The ECG revealed a new significant $Q$ wave in III and prominent T waves in the precordial leads V2 and V3. Transthoracic echocardiography showed a new akinesia of the posterior wall. The subsequent coronary angiography revealed a new unstable plaque in the 
first branch of the left circumflex coronary artery (Figure 1B) being absent 3 weeks earlier (Figure 1A). There, a direct bare-metal stent was deployed.

One week later, the kidney-transplant removal surgery had to be performed urgently due to urosepsis. Within the explanted renal allograft, the histological analysis revealed abscess formation and a prevalent vasculitis as sign of chronic vascular rejection (Figure 2A). As a new finding, a moderately differentiated renal- cell carcinoma (G2, pT1a, pN0, L0, V0) with a diameter of $2.5 \mathrm{~cm}$ was found (Fig. 2B and $2 \mathrm{C}$ ). The tumor was restricted to the renal transplant showing no signs of invasion. In abdominal and thoracic computed tomographies, lymphnode or organ metastases were not found. Euglycemia and normal blood pressure were maintained before and after surgery. $\mathrm{HbA} 1 \mathrm{c}$ was $5.3 \%$.

Within six days following surgery, the patient experienced a third troponinpositive, unstable angina when inflammation-parameters were unprecedentedly high with a CrP of $200 \mathrm{mg} / \mathrm{L}$. Creatinine kinase remained normal. Echocardiography showed no change, in spite of new negative $T$ waves in the precordial ECG leads V4 - V6. Under conservative therapy including intravenous heparin and antibiosis, cardiac situation stabilized, post-surgery infection consolidated.

Within 10 days after renal-transplant removal surgery, albumin plasma concentration increased from $25.5 \mathrm{~g} / \mathrm{L}$ to $32.9 \mathrm{~g} / \mathrm{L}$. During hospitalization 4 months after surgery, a scheduled coronary angiography was unrevealing. However, at that time, CrP still was elevated $(60 \mathrm{mg} / \mathrm{L})$ suggesting the presence of additional sources of inflammation. The clinical examination including a sonographic exam of arteriovenous fistula for hemodialysis access was unrevealing. After discharge, the patient was not rehospitalized for acutecoronary syndrome within the next 12 months. 


\section{Discussion and Conclusion}

This case suggests that peak systemic inflammation may coincide with acute coronary syndromes. Once the renal allograft ceased to function due to pyelonephritis and due to chronic allograft rejection, increased systemic inflammation may have facilitated the occurrence of plaque ruptures leading to acute coronary syndromes. This view is supported by sequential coronary angiograms within 3 weeks. As soon as systemic inflammation was consolidated, the patient remained event-free, as far as acute coronary syndromes are concerned. After kidney transplantation, medical immunosuppressive therapy may predispose to infections. Once the main source of infection has been identified, other secondary sources of infection, e.g. hemodialysis catheter (7) and/or infective endocarditis need to be ruled out, if systemic inflammation still persists. In the present case, there was no clinical sign of arteriovenous-fistula infection, no secondary source of inflammation was found.

As a limitation, no cause-consequence relationship between inflammation and acute coronary syndromes may be established from a single case. However, the timely coincidence points to the possibility of a contribution of systemic inflammation to the occurrence of cardiovascular events. Coronary plaque rupture is known to be facilitated by pro-inflammatory cytokines (8). Besides local inflammatory processes leading to coronary-plaque instability, a more generalized inflammatory response may affect the whole coronary tree. There, CrP synthesized in the liver upon interleukin-6 stimulation, represents a candidate mediator linking inflammation with occurrence of acute coronary syndromes (9). In an animal model of atherosclerosis, CrP transgene expression accelerated aortic atherosclerosis (10), while therapeutic inhibition of $\mathrm{CrP}$ improved outcome of experimental myocardial infarction (11). Functional studies on neutrophils and human endothelial cells indicate that monomeric $\mathrm{CrP}$, but not pentameric or native CrP, leads to neutrophil-granulocyte (12) and to endothelialcell activation (13). Increased systemic inflammation adversely affects mortality in patients with chronic kidney disease, stage 3 or 4 of (14). In addition, overall 
and cardiovascular mortality correlate with the estimated glomerular filtration rate (15). Future research needs to determine the individual roles and mechanisms of uremic toxins and inflammation for cardiovascular outcomes. To contain a possible role of $\mathrm{CrP}$ on acute coronary-artery disease progression, adsorptive techniques to therapeutically lower plasma CrP may be employed on an individual basis (16).

In summary, from this case a contributory role of inflammation on acute progression of coronary heart disease is assumed. Anti-inflammatory strategies, such as the removal of a failed, super-infected renal allograft, need to be considered in patients with therapy-resistant systemic inflammation to avoid cardiovascular complications. 


\section{Declarations}

Ethics approval and consent to participate

Not applicable

Consent for publication

Written informed consent to publish patient-related information was obtained from the patient. The signed informed consent is on file. A copy of the consent form is available for review by the Editor of the journal.

\section{Availability of data and material}

All relevant data were included in the manuscript.

\section{Competing interests}

None of the authors has competing interests.

\section{Funding}

Not applicable

\section{Acknowledgement}

The authors wish to thank the patient for providing his consent for the publication. 


\section{Authors' contributions}

RUP and SSD were attending doctors of the patient. RUP drafted the paper.

SSD gave critical input. AT critically contributed to contents concerning the

histological specimen. All authors contributed to the discussion and approved the content of this manuscript. 


\section{Figure legends}

Figure 1: Coronary angiogram of the left coronary artery with left anterior descendant and left circumflex coronary arteries A) at index hospitalization, B) 3 weeks later, at a second hospitalization for acute coronary syndrome. Arrows indicate the position before and after new development of a culprit lesion within a branch of the LCX.

\section{Figure 2:}

A) Severe chronic inflammation of the graft with dilated cysts and fibrosis. (Hematoxylin-Eosin; original magnification x 20);

B) Moderately differentiated renal cell carcinoma (Hematoxylin-Eosin; original magnification x 20);

C) Immunohistochemical visualization of cytokeratin within the tumor (brown reaction product: anti-cytokeratin (1/400, Clone; MNF 116; Dako, antibody for $2 \mathrm{~h}$ at room temperature; original magnification $\times 25$ ). 


\section{References}

1. Danesh J, Wheeler JG, Hirschfield GM, Eda S, Eiriksdottir G, Rumley A, Lowe GD, Pepys MB, Gudnason V. C-reactive protein and other circulating markers of inflammation in the prediction of coronary heart disease. $\mathrm{N}$ Engl J Med. 2004; 350:1387-1397.

2. Koenig W, Löwel H, Baumert J, Meisinger C. C-reactive protein modulates risk prediction based on the Framingham Score: implications for future risk assessment: results from a large cohort study in southern Germany. Circulation. 2004;109: 1349-1353.

3. Paul M Ridker, M.D., Eleanor Danielson, M.I.A., Francisco A.H. Fonseca, M.D., Jacques Genest, M.D., Antonio M. Gotto, Jr., M.D., John J.P. Kastelein, M.D., Wolfgang Koenig, M.D., Peter Libby, M.D., Alberto J. Lorenzatti, M.D., Jean G. MacFadyen, B.A., Børge G. Nordestgaard, M.D., James Shepherd, M.D., James T. Willerson, M.D., and Robert J. Glynn, Sc.D. for the JUPITER Study Group*: Rosuvastatin to Prevent Vascular Events in Men and Women with Elevated C-Reactive Protein. N Engl J Med. 2008; 359:2195-2207

4. Tanaka A, Shimada K, Sano T, Namba M, Sakamoto T, Nishida Y, Kawarabayashi T, Fukuda D, Yoshikawa J. Multiple plaque rupture and Creactive protein in acute myocardial infarction. J Am Coll Cardiol. 2005; 45:1594-1599.

5. Buffon A, Biasucci LM, Liuzzo G, D'Onofrio G, Crea F, Maseri A. Widespread coronary inflammation in unstable angina. N Engl J Med. 2002, 347: 5-12.

6. Jialal I, Devaraj S, Venugopal SK. C-reactive protein: risk marker or mediator in atherothrombosis? Hypertension. 2004; 44: 6-11.

7. Nassar GM, Ayus JC. Infectious complications of the hemodialysis access. Kidney Int 2001; 60:1-13.

8. Ko YG, Jung JH, Park S, Choi E, Joung B, Hwang KC, Ha JW, Choi D, Jang Y, Chung N, Shim WH, Cho SY. Inflammatory and vasoactive factors in the aspirate from the culprit coronary artery of patients with acute myocardial infarction. Int J Cardiol. 2006;112:66-71

9. Biasucci LM, Liuzzo G, Grillo RL, Caligiuri G, Rebuzzi AG, Buffon A, Summaria F, Ginnetti F, Fadda G, Maseri A. Elevated levels of C-reactive protein at discharge in patients with unstable angina predict recurrent instability. Circulation 1999, 99: 855-860. 
10. Paul A, Ko KW, Li L, Yechoor V, McCrory MA, Szalai AJ, Chan L. C-reactive protein accelerates the progression of atherosclerosis in apolipoprotein Edeficient mice. Circulation 2004, 109: 647-655.

11. Szalai AJ, McCrory MA, Xing D, Hage FG, Miller A, Oparil S, Chen YF, Mazzone M, Early R, Henry SP, Zanardi TA, Graham MJ, Crooke RM. Inhibiting C-reactive protein for the treatment of cardiovascular disease: promising evidence from rodent models. Mediators Inflamm. 2014; 2014:353614

12. Khreiss T, József L, Potempa LA, Filep JG. Loss of pentameric symmetry in C-reactive protein induces interleukin-8 secretion through peroxynitrite signaling in human neutrophils. Circ Res. 2005; 97:690-697.

13. Khreiss T, József L, Potempa LA, Filep JG. Conformational rearrangement in C-reactive protein is required for proinflammatory actions on human endothelial cells. Circulation 2004; 109:2016-2022.

14. Menon V, Greene T, Wang X, Pereira AA, Marcovina SM, Beck GJ, Kusek JW, Collins AJ, Levey AS, Sarnak MJ. C-reactive protein and albumin as predictors of all-cause and cardiovascular mortality in chronic kidney disease. Kidney Int. 2005; 68:766-772.

15. Go AS, Chertow GM, Fan D, McCulloch CE, Hsu CY: Chronic kidney disease and the risks of death, cardiovascular events, and hospitalization. $\mathrm{N}$ Engl J Med. 2004; 351:1296-1305.

16. Mattecka S, Brunner P, Hähnel B, Kunze R, Vogt B, Sheriff A. PentraSorb C-Reactive Protein: Characterization of the Selective C-Reactive Protein Adsorber Resin. Ther Apher Dial. 2019;23:474-481 